\title{
Introduction: the panorama of development policy
}

\author{
Habib Zafarullah and Ahmed Shafiqul Huque
}

\section{INTRODUCTION}

The landscape of development policy is vast and varied. In all societies of the contemporary world, development is crucial both as a means and an end. Unlike in the past, when the underdeveloped countries invariably had to strive hard across many sectors - economic, political and social - to accomplish the goals of development, the developed countries also now encounter similar challenges despite having attained significant social and economic progress. Thus, the process of formulating and implementing development policies is a core function in all states, regardless of their size, location, level of prosperity, ideological inclination and strength of the economy.

Managing development remains a consistent challenge for many countries as they struggle to perform the essential activities of governing with limited resources and weak institutions. These handicaps have forced governments - in developing countries, in particular - to concentrate on only a limited number of areas for improvement, notably those that allow regimes to showcase their 'accomplishments' for gaining political advantages locally and globally. For that reason, the more pressing problems of societies are usually overlooked, with merely a few privileged groups reaping benefits from development initiatives.

Since the late twentieth century, the compass of development has been widening and multiplying the range of policies and strategies for a variety of development sectors - some traditional, others contemporary. The policy process has increasingly become intricate and unwieldy, given the rise of unfamiliar challenges often hard to assuage, such as recurring financial crises, climate change and the global coronavirus pandemic. Issues in an uncertain milieu keep accumulating, testing national governments and international policy regimes' capability to cope with them. Global conventions and international organizations, with the support of regional bodies, national governments and civil society, make relentless efforts to find solutions for a plethora of issues. But universal solutions to local problems, more often than not, prove futile. In many developing countries, policymakers - uninformed of the gravity of problems because of flaws in policy research or inaccuracies in the collection, assimilation and integration of qualitative and quantitative data - make incorrect assessments that compromise the quality of policies. Critical thinking is indispensable for sound policymaking, but this requirement is not always acknowledged or internalized.

The social and economic progress of societies and protection of the planet will depend on robust development governance (DG) - a composite process that blends democratic values, governance norms and environmental standards in a globalized setting. This will require nations and institutions to develop common goals, accommodate differences and forge partnerships. It should also help augment cooperation, collaboration and co-production between the state and various development stakeholders and contribute to creating and allocating value 


\section{Handbook of development policy}

throughout society. Sound DG works towards humanity's total advancement from social, cultural, economic, political, technological and environmental perspectives for building sustainable livelihoods. An embedded development culture within the development governance framework provides a rich source of 'identity, innovation and creativity' that boosts human capabilities, generates equity and deepens social sustainability (Chambers \& Conway, 1991; United Nations Educational, Scientific and Cultural Organization [UNESCO], 2010).

An assortment of cultural values derived from a society's historical trajectory, social mores, political conventions, economic practices and legal norms inform and influence the modalities of DG for attaining the goals of development. To be productive, development governance needs dynamism bolstered by efficiently functioning levers. One such lever is an inclusive policy process cognisant of temporal and spatial dimensions, open to appropriate policy choices based on evidence and stakeholder consultation, sensitive to citizen perceptions, empathic to both political signals and scientific judgment, mindful of external influences and integrative of advanced implementation drivers and instruments (Organisation for Economic Co-operation and Development [OECD], 2013; UNESCO, 2015). Inclusive policymaking information based, evidence driven and citizen centred - has the potential to be receptive to diverse views and demands emanating from the policy environment. An enlarged space for people, groups and networks outside the state structure will provide a progressive and favourable perspective on social synergy (United Nations Development Programme [UNDP], 2002; Zafarullah \& Huque, 2012).

Both vertical and horizontal linkages within government and coordinated exchanges with non-state actors and institutions can create the conditions for collaboration, facilitate the prudent use of resources and ideas, enhance civic participation and empower people. The interface can be a useful tool in building social capital within a democratic edifice in which policymaking and implementation, linked through intermediate phases, transpire. The inclusive policy phenomenon being an integral dimension of 'open government', edifies transparency, accountability, integrity and participation, which constitute the critical elements of governance (Fung \& Weil, 2010). These values enhance the quality of policies by keeping policymakers and policy proponents discrete in their roles, and citizens and stakeholders optimistic of what to expect from the process. Indeed, the complementarity between transparency and participation creates opportunities for deliberative policymaking (Meijer, Curtin \& Hillebrandt, 2012; Noveck, 2009; O’Reilly, 2010; Piotrowski \& Borry, 2010). This book highlights the importance of the critical role that development policy can play in achieving these objectives.

\section{THE GLOBAL POLICY ARCHITECTURE}

The world is challenged by an ever-expanding population, unfavourable effects of globalization, the adverse impact of climate change and global warming, endemic poverty, rising inequality, health hazards, poor sanitation, food shortages, inadequate education systems, gender inequality, impaired governmental performance, declining human rights, backsliding freedom, lop-sided trade and investment, widespread corruption and environmental degradation among many other problems. Thus, social, economic, political, environmental, technological and legal issues are now at stake, with implications for sustained economic and social well-being, climate control and environmental protection, macroeconomic management, infrastructure 
building, citizenship and empowerment. Some of these problems can be managed at the national level, while others need to be approached on the global plane through multilateral engagements of supra-national institutions, civil society organizations, transnational corporations, international think-tanks, policy networks, and the global capital market to harmonize overarching laws and regulations, and enforce international accords and protocols for the universal good of societies, nations and the world (Commission on Global Governance, 1995; Triandafyllidou, 2017). Managing global and regional risks, with implications for development at various levels, is the core objective of 'global governance' (Wilkinson \& Hughes, 2003).

Global governance is concerned with 'systems of rule at all levels of human activity - from the family to the international organization - in which the pursuit of goals through the exercise of control has transnational repercussions...in an ever more interdependent world' (Rosenau, 1995, p. 13). However, the mix of diverse institutions playing specific roles remains insulated from any forms of accountability or surveillance, as there is no formally organized body to regulate them. Mainly, a network of intergovernmental organizations serves as a primary mechanism 'through which civil society and corporate interests are effectively embedded in the global policy process' (Held \& McGrew, 2007, p. 156).

The global policy process is ideologically influenced by neoliberalism endorsed by institutions that matter in development, such as the United Nations (UN) and its agencies, the International Monetary Fund (IMF), the World Bank, regional development banks and the World Trade Organization (WTO). The UN's fundamental premise has been multilateralism and international cooperation for improving people's well-being and creating 'the conditions [for] economic and social progress and development' to raise living standards (UN, 1945, p. 11). Even though the purpose of multilateralism and the presence of hierarchically disordered and analogous international organizations have been critically reviewed from various angles (see Alter \& Meunier, 2009; Morse \& Keohane, 2014), the UN et al. continue to influence economic and social development, climate change and environmental protection, gender equality and empowerment, democracy and human rights, disaster risk reduction and human settlements. Through the decades, the world body has been promoting the idea of self-sustaining growth by urging member countries to adopt a more comprehensive approach to development. The focus should be on an organized national planning exercise that lays emphasis on the human factor, enlarged employment opportunities, augmented trade and investment, developed and sustained natural resources, gender equality and stimulated research on social issues. These concerns for development at the country level found eloquence in the UN's Millennium Development Goals (MDGs, 2000-15), followed by the Sustainable Development Goals (SDGs, 2015-30).

Development policy reform at the country level has been influenced by both the MDGs and SDGs and the so-called 'Washington Consensus' prescriptions. National political leaders and policymakers generally go by their guidelines in fulfilling growth and development targets, but at the cost of compromising some of their policy autonomy. Arguably, 'the developing nations are squeezed between the demands of international finance and industrial capital, the rules generated and enforced by the international establishments, and the conditionalities of aid. There is little room for them to maneuver' (Zafarullah \& Huque, 2012, p. 22). However, there are qualms about the viability of sustainable development in a climate of intrusive neoliberalism that continues to influence public policies in both developed and developing nations (Barkin, 2000; Buscher, Dressier \& Fletcher, 2014; Raco, 2005). 


\section{Handbook of development policy}

On another front - climate change and environmental protection - global conventions and protocols have led to policy changes at the national and regional levels. The first UN Conference on the Human Environment emphasized the environment as a key global concern and focused on economic development, air and water pollution and human well-being (UN, 1972). The UN Conference on Environment and Development (Earth Summit) of 1992 advanced Agenda 21 - a set of strategies for social and economic development and conserving and managing resources and protecting biological diversity. The Kyoto Protocol (1998) consolidated and further enhanced Agenda 21 and operationalized the 1992 United Nations Framework Convention on Climate Change (UN, 1972, 1992, 1998).

The pre-eminence of globally articulated developmental and environmental policies places national governments in developing nations under pressure to resolve diverse problems in their own backyard through policies and strategically planned action. If ever, national policymakers seldom get the opportunity to develop an understanding and awareness of problems on the ground and address them with appropriate solutions. The political leadership is not immune to external influences for geopolitical reasons and cannot take a stand to protect their country's interests. In authoritarian political systems, stakeholder involvement, public opinion or the attentive public barely receive attention in the policy process. Inclusivity remains conspicuous by its absence.

The COVID-19 pandemic has exposed the democratic deficit in development governance and, especially, development policymaking. With limited stakeholder input and citizens in disarray, policymaking has more or less become the exclusive domain of politicians and bureaucrats who are pulled in different directions between the need to meet political ends (primarily, regime maintenance) and follow scientific advice (to minimize infection). With the inclusive and direct deliberative policy process all but stalled in a virtual world, the possibility of assimilating diverse perspectives has been fading. A cultural split and a lack of mutual trust between policymakers and scientists seem to have emerged (Cairney \& Wellstead, 2020; Kwon, 2020).

\section{SCOPE AND PLAN OF THE BOOK}

This Handbook has put together 46 chapters on development policy from scholarly and practical perspectives on a range of development sectors - economic, social, political, technological and environmental. The research presented in the various chapters provides critical analyses of complex and often perplexing issues relating to the areas addressed. Apart from general issues, a range of development sectors and geographical regions has been covered from empirical standpoints. Contributors to the book include 64 leading scholars and practitioners in development, specializing in policy matters. They represent universities, think tanks, non-governmental organizations and international development agencies. The book is organized into five parts.

\section{Part I: Exploring the Field}

Part I of the book offers an exploration of the field of development policy from diverse perspectives. Zafarullah and Huque open the discussion with an overview and analysis of the trajectory of thought and actions in development policy and emphasize the need for establish- 
ing linkages between ideas and practices and creating an enabling environment for inclusive policymaking and implementation to make the process meaningful and effective.

Nederveen Pieterse reviews the significant shifts in development thinking and practice in the twenty-first century. He highlights the shift in global development relations, with developing nations becoming the drivers of the world economy. The North's 'we develop them' demeanour has been replaced by the South's 'we develop' posture. The move towards multipolar development with developing countries playing a more critical role has tampered with North-South relations. Conteh's analysis pieces together the challenges of development, governance and policymaking within one framework to highlight the challenges faced by developing countries. The chapter suggests multilevel governance as a tool for dealing with the complexities resulting from the tension between the domestic and international institutional contexts.

Chowdhury recognizes the importance of inclusive economic growth for addressing inequalities resulting from strategies relating to liberalization, privatization, stabilization and globalization. Pointing to the risks to sustainability of growth and social political stability, the chapter argues that progressive taxation, public infrastructure investment, public social expenditure and universal social protection could reduce inequality. The issue of equality in development policy is the focus of Anderson's analysis. The author identifies problems in the areas of social policy, education, macroeconomic stability, foreign trade and investment, and finance. The chapter cautions that policies designed to reduce inequality could affect the long-run economic performance of a country but is optimistic about equity-enhancing policy reforms.

Quibria delves into the issue of poverty alleviation by referring to two main approaches of inclusive growth and empowerment. Drawing upon the experience of Asian countries that have performed well in reducing poverty, the chapter offers projections of policy effectiveness in the post-pandemic developing world. Andreassen looks at the shifting approaches to development and asserts the importance of human rights for ensuring economic development and social justice. The chapter takes a governance approach and argues that a human rights framework is critical for development policymaking and implementation.

The premise of Shrestha's analysis seeks to find a link between social networks, social capital and development. The chapter argues that internally cohesive communities have the ability to build networks and develop relationships with the state for achieving favourable outcomes in development policy. Lynch and Khan explore the evolution of environmentalism and outline the changes in the nature of the state. They argue that the process of development changed from a means of state formation and stability to intense interstate competition that emphasized the economic logic of capitalist reinvestment. Drydyk and Keleher discuss the critical but under-researched issue of development ethics and separate 'worthwhile' and 'undesirable' aspects of policies based on several values. They advance a strategy for 'avoiding errors' to 'strengthen...judgements about right and wrong ways of going about development'. The chapter points out the lack of attention to development ethics, accountability to stakeholders, and epistemic challenges due to credibility issues and prejudice.

Alam's chapter presents a review of the various events and protocols that were expected to offer guidelines to deal with the environmental crisis confronting the world, and laments that the threat remains unmitigated. An assessment of the efforts and contribution of the states participating in the agreements leads to the conclusion that international cooperation is essential for addressing global environmental degradation. Pogge believes the move from 
MDGs to SDGs has implications for development because the efforts will not be restricted to developing and poor countries. Recognizing the potential of more extensive coverage by the SDGs, the chapter notes the risk of a structural defect arising out of loopholes for countries to evade their obligations and cautions about the issue of legal enforcement that could minimize the impacts of SDGs. Quadir reviews South-South cooperation's prospects by analysing the relationships between aid providers and recipients and their consequences. He identifies the declining effectiveness of the conventional aid delivery mechanism and the emergence of new actors in the international aid regime. The chapter expresses concern over the possible return of the modernization model that was challenged and rejected by many post-colonial states.

\section{Part II: Development Issues}

Part II of the book is devoted to the analysis of development issues. Momsen reviews the evolution of gender issues in development that culminated in the emergence of policies relevant to women and their mainstreaming in development. The author recognizes the empowerment of women and the success of the MDGs in achieving gender equality and expects the SDGs to result in further improvements. Bezu explores rural development policy concerning smallholder farming, the agri-food value chain, rural non-farm economy and climate change. The chapter recognizes some improvement in productivity, market integration, tenure and access to technology, but notices continuing challenges in some countries due to lack of progress in structural transformation, access to land and climate change.

Dolla and Laishram analyse policies on infrastructure that contribute to development governance. They discuss procurement issues in sustainable infrastructure building and identify problems in the decision process at various levels and weaknesses in the delivery models that require transformations in development policy formulation. Brogaard presents a development policy perspective of public-private partnership (PPP) with reference to the Global Compact and SDGs. Based on data from the World Bank and the UN, this chapter explores the concept and approaches of PPP and highlights its primacy in development policy.

Hartmann presents a review of research and practices in anti-corruption measures. He identifies major shifts in approaches and adds that the focus on crime, institutional weakness and power and politics were used to determine anti-corruption strategies. The chapter argues that anti-corruption policies will be more effective by indirectly addressing corruption and being consistent with political and economic contexts. Clarke discusses the challenge of protecting clients and staff of international non-governmental organizations from exploitation, abuse and harassment. Based on an examination of the Oxfam scandal of 2018, the chapter recommends accountability and transparency within a framework of high-quality, culturally inclusive, learning-based management and the introduction of international or transnational regulation.

Lauridsen points to the resurgence of interest in industrial policy after the Global Financial Crisis and reviews the nature of strategic industrial policy. The chapter highlights the importance of institutional capacity and concentrates on the issues of value chains and greening of industrial policy. Momen approaches development policy in the neoliberal world from a social citizenship perspective. The chapter discusses three models of social citizenship to argue for transparency in allocating tax revenues to social rights, ensuring social rights to non-citizens and evaluating development with these points of reference. In view of the increasing voluntary and involuntary displacement of people, Meral and Barbelet use the humanitarian policy lens to examine development policy. The chapter analyses the challenges and opportunities faced 
in formulating and implementing policies to offer lessons that could help adjust practices for better outcomes.

Terberger and Winkler acknowledge microfinance as an essential element of development policy that has become evident over the past four decades. The chapter critically reviews these developments and proposes strategies for contributing to poverty reduction, economic development and robust financial inclusion policies. Tiessen and Lough consider aid policies and priorities to ascertain the impact of volunteers in international development. The chapter reviews the core policy objectives regarding public diplomacy and skills building and advances an alternative form of public diplomacy for interactive development. Tomossy reviews the changing landscape of global public health law and traces its linkages to development policy. Pointing to the need for recognizing health as a human right, the chapter reflects on the role and effectiveness of domestic and international institutions and warns of major challenges insofar as institutional coordination, national sovereignty and governance influence health policies at the country level.

Tovar offers a policy perspective on social safety nets (SSNs) as a key component to eliminating poverty. The chapter presents an extensive discussion of the outcome of SSNs in various forms and recommends strategies to achieve this core Sustainable Development Goal. Tabassum undertakes an examination of climate change by pointing out the contradiction between guidelines for responses to the crisis through policies of adaptation and/or mitigation. Using a framework of 'climate capitalism' and 'carbon colonialism', the chapter evaluates climate change adaptation and mitigation policies.

\section{Part III: Policy Mechanics}

Part III includes a set of chapters that deal with policy mechanics. Turner makes the point that it is unrealistic to find 'one best way' for policy success. However, there is potential for making development policies effective by emphasizing environmental awareness, acknowledging capacity constraints, being adaptable and promoting participation. Saguin and Howlett reveal a disconnect between development policy studies and practice and the problem of disregarding the role of policy actors. They suggest a framework to understand the role of transnational policy networks in the formulation of development policy. The chapter highlights the roles played by epistemic communities, instrument constituencies and advocacy coalitions.

Jongruck and Gunawong consider the implications of network governance for the SDGs. They argue that their achievement would require collaboration between state and non-state actors at all levels. Based on a case study of the haze problem in Thailand, they propose a multi-level network governance framework as an approach for the achievement of SDGs. Rahman analyses the tension between aid and ownership of development policy. The chapter describes the context of the issue, efforts to assume ownership by recipient countries and an analysis of existing patterns to advocate for a fair and autonomous approach to development partnerships.

Zambrano highlights the role of public institutions and stakeholders in the rapidly developing ICT arena that requires rapid adjustments to keep up with new challenges. The chapter traces the links between public policy, models of development and digital technologies to propose new research areas. Ton explores the impact of policy on learning and accountability in private sector development. Elaborating on the diverse approaches to the issue, the chapter 
proposes a structured process of 'contribution analysis' - a theory-based evaluation to address challenges.

\section{Part IV: Regional Focus}

Part IV devotes attention to development policy ideas and practices in various regions of the world. Ahmed looks at trends and the impacts of capital flow on selected Asian countries' monetary policies and assesses the consequences of the Asian and Global Financial Crises in 1987 and 2007, respectively. The chapter analyses the policies adopted to address the problem and emphasizes that lessons drawn by these countries will strengthen financial institutions in the region and protect them from external turmoil. Díaz Ríos, Poirier and Dion assess recent trends in education and health policy innovations in 19 Latin American countries through a lens of social citizenship. The chapter argues that some progress was attained in school attendance and access to healthcare, but the benefits were not equitably distributed, and the outcomes remain unequal.

Hodge examines inclusive education policy in the Eastern Caribbean states with reference to hindering and enabling factors because it requires collaboration and participation by stakeholders. The chapter finds that the success of inclusive strategies requires sustainable education policy systems. Koehler, Kühner and Neff present a comparative overview of social policy in five South Asian countries. A discussion of innovations in the key areas of social policy, inputs and human development outcomes shows substantial gaps in social provision. The chapter recommends more fiscal space and civil liberties to address the power relationships that affect the outcomes.

Schmidt-Vogt traces the evolution of community-based forestry that emerged from a shift towards the needs of the local population, decentralized and joint forest management with participation by the community. The chapter proposes community-based forestry as a framework for forest resources management for benefiting the communities, promoting rural development and building local institutions. Siddiquee and Hamiduzzaman review and assess policies to address the problems of deprivation and vulnerability in Southeast Asia. They recognize some of the region's key policy initiatives towards poverty alleviation, social protection and improved service delivery.

\section{Part V: Country Cases}

Part V includes chapters that present discussion and analyses based on specific countries. Feldman studies rural social relations at different stages of the implementation of projects in Bangladesh. The chapter is based on a comparison of historical records of 'transfer notes' by local administrators and reveals that local bureaucrats play a more decisive role compared to the political leadership. Mensah, Bawole, Hossain and Kumasey examine the mid-term development planning process as a policy tool in Ghana and demonstrate that human resource capacity constraint is the biggest challenge that needs to be addressed.

Quah evaluates the role and performance of the Anti-Corruption Commission (ACC) in Bangladesh. A review of the strategies for combating corruption in Asian countries suggests that the model adopted by Bangladesh will not be successful without political will, fully fledged autonomy for the public integrity regime and authority to enforce anti-corruption laws. Mok uses China's example to illustrate the engagement of non-governmental organizations 
in improving social service provision and promoting social harmony. The chapter compares different approaches for enhancing service delivery, underlines the changing relationships between the state, the market and the third sector to highlight the Chinese experience in development policy.

Dhar acknowledges the success of multilateral institutions in primary and secondary education in Bangladesh and explores the use of subvention to enhance efficiency and effectiveness in schools. The chapter analyses the shifts in approach that are driven by neoliberalism and market principles, resulting in compromises that are influenced by political motives. Nair examines the impact of decentralized development in the Indian state of Kerala to understand the status of marginalized communities. The chapter finds that caste and religion are the main barriers to empowerment and capacity building, and bureaucratic obstacles further influence this. Finally, Lata and Khan point out the problem of government restrictions and illegal encroachment by private parties that deny the urban poor access and use of public space to earn a livelihood in Bangladesh. The chapter explains the problem with reference to exclusionary elite-based governance arrangements that severely affect the poor and proposes inclusive governance for their empowerment to guarantee right to the city, access to public space and open up livelihood options for them to move out of poverty.

The chapters in this Handbook provide diverse perspectives on policies and their implications for development, insights into the dynamics of the policy process, an assortment of specific policy issues, and a few regional and country cases highlighting the field's expansive nature.

\section{REFERENCES}

Alter, K.J., \& Meunier, S. (2009). The politics of international regime complexity. Perspectives on Politics, 7(1), 13-24.

Barkin, D. (2000). Overcoming the neoliberal paradigm: sustainable popular development. Journal of Developing Societies, 16(1), 163-80.

Buscher, B., Dressier, W., \& Fletcher, R. (2014). Environmental Conservation in the Neoliberal Age. Tucson, AZ: University of Arizona Press.

Cairney, P., \& Wellstead, A. (2020). COVID-19: effective policymaking depends on trust in experts, politicians, and the public. Policy Design and Practice, 4(1), 1-14.

Chambers, R., \& Conway, G.R. (1991). Sustainable rural livelihoods: practical concepts for the 21st century. IDS Discussion Paper No. 296. Accessed 21 December 2020 at https://opendocs.ids.ac.uk/ opendocs/bitstream/handle/20.500.12413/775/Dp296.pdf?sequence=1.

Commission on Global Governance (1995). Our Global Neighborhood. Oxford: Oxford University Press.

Fung, A., \& Weil, D. (2010). Open government and open society. In D. Lathrop \& L. Ruma (eds), Open Government: Collaboration, Transparency, and Participation in Practice (pp. 105-13). Beijing: O'Reilly Media.

Held, D., \& McGrew, A. (2007). Globalization/Anti-Globalization: Beyond the Great Divide (2nd edition). Cambridge, UK: Polity Press.

Kwon, D. (2020, 1 September). Science and policy collide during the pandemic. The Scientist. Accessed 21 December 2020 at https://www.the-scientist.com/careers/science-and-policy-collide-during-the -pandemic-67882.

Meijer, A.J., Curtin, D., \& Hillebrandt, M. (2012). Open government: connecting vision and voice. International Review of Administrative Sciences, 78(1), 10-29.

Morse, J.C., \& Keohane, R.O. (2014). Contested multilateralism. Review of International Organizations, $9,385-412$. 
Noveck, B.S. (2009). Wiki Government: How Technology Can Make Government Better. Washington, DC: Brookings Institution Press.

O'Reilly, T. (2010). Government as a platform. In D. Lathrop \& L. Ruma (eds), Open Government: Collaboration, Transparency and Participation in Practice (pp. 11-39). Beijing: O'Reilly Media.

Organisation for Economic Co-operation and Development (OECD) (2013). Inclusive policy making. In OECD, Government at a Glance 2013 (pp. 146-8). Paris: OECD Publishing.

Piotrowski, S.J., \& Borry, E. (2010). An analytical framework for open meetings and transparency. Public Administration and Management, 15(1), 138-76.

Raco, M. (2005). Sustainable development, rolled-out neoliberalism and sustainable communities. Antipode, 37(2), 324-47.

Rosenau, J.N. (1995). Governance in the twenty-first century. Global Governance, 1, 13-43.

Triandafyllidou, A. (ed.) (2017). Global Governance from Regional Perspectives: A Critical View. Oxford: Oxford University Press.

United Nations (UN) (1945). Charter of the United Nations and Statute of the International Court of Justice. New York: UN. Accessed 21 October 2020 at https://treaties.un.org/doc/publication/ctc/ uncharter.pdf.

United Nations (UN) (1972). Report of the UN Conference on the Human Environment. New York: UN. Accessed 28 November 2020 at http://undocs.org/en/A/CONF.48/14/Rev.1.

United Nations (UN) (1992). Agenda 21. New York: UN Department of Economic and Social Affairs. Accessed 28 November 2020 at https://www.un.org/en/events/pastevents/pdfs/Agenda21.pdf.

United Nations (UN) (1998). Kyoto Protocol to the United Nations Framework Convention on Climate Change. New York: UN. Accessed 28 November 2020 at https://unfccc.int/resource/docs/convkp/ kpeng.pdf.

United Nations Development Programme (UNDP) (2002). Human Development Report: Deepening Democracy in a Fragmented World. New York: UNDP.

United Nations Educational, Scientific and Cultural Organization (UNESCO) (2010). The Power of Culture for Development. UNESDOC Digital Library. Accessed 21 December 2020 at https://unesdoc .unesco.org/ark:/48223/pf0000189382.

United Nations Educational, Scientific and Cultural Organization (UNESCO) (2015). Analytical Framework for Inclusive Policy Design: Of Why, What and How. Paris: UNESCO.

Wilkinson, R., \& Hughes, S. (eds) (2003). Global Governance: Critical Perspectives. Abingdon, UK: Routledge.

Zafarullah, H., \& Huque, A.S. (2012). Managing Development in a Globalized World: Concepts, Processes, Institutions. Abingdon, UK: Routledge. 